\title{
Temporal Change in the Match Performance of Football Referees during Youth Top-level Matches: Influence of Match Technical-tactical Data in Same
} Matches

\author{
Yoshihiko Ishihara', Hisashi Naito ${ }^{1,2}$, Satoshi Ishizaki ${ }^{3}$ and Masafumi Yoshimura ${ }^{2}$ \\ ${ }^{1}$ Institute of Health and Sports Science \& Medicine, Juntendo University, 1-1 Hirakagakuendai, Inzai, Chiba 270-1695, Japan \\ hnaitou@juntendo.ac.jp \\ ${ }^{2}$ Graduate School of Health and Sports Science, Juntendo University, 1-1 Hirakagakuendai, Inzai, Chiba 270-1695, Japan \\ ${ }^{3}$ Shibaura Institute of Technology, 307 Fukasaku, Minuma, Saitama 337-8570, Japan \\ [Received July 28, 2016; Accepted March 28, 2017; Published online April 17, 2017]
}

\begin{abstract}
This study aimed to examine temporal change in the physical demands with respect to a referee's running distance and speed, and heart rate (HR) during Japanese high-school (U-18) and university (U-22) football matches, and to investigate the match technical-tactical data. Additionally, we compared the physical demands and match performance of referees during the U-18 and U-22 matches. Physical performance (15 Hz global positioning system device) and HR of 20 Japanese referees (age, 26.3 \pm 3.4 years) were measured from 20 matches (one match dataset per referee). All matches were video filmed to calculate the distance from a foul and match technical-tactical data (passes, shots, fouls, offense-defense turnovers, and penetrations into the attacking zone). We found that physical demands were temporarily increased in the last stage of a match. Some technical-tactical data similarly increased in the same stage, suggested that the referees during the $\mathrm{U}-18$ and $\mathrm{U}-22$ matches are required to move around each penalty area and keep up with play in the last stage of a match. Referees' physical demands and match performance were not different between the $U-18$ and $U-22$ matches.
\end{abstract}

Keywords: game analysis; team sports; heart rate; global positioning system; soccer

\section{Introduction}

Football referees implement the rules of the game and are responsible for controlling the behavior of players during a football match (Castagna et al., 2007). Consequently, they are required to keep up with play because they must be in the best position to observe play in order to make correct decisions (Weston et al., 2012, Weston et al., 2010). To achieve an appropriate distance from fouls, referees are intermittently required to demonstrate high intensity activities during a football match. For example, football referees in top Danish league and international matches were reported to cover $10.1 \mathrm{~km}$ and $10.3 \mathrm{~km}$, respectively, with $17 \%$ and $19 \%$ of the respective distances covered by high-intensity running (HIR $\geq 15 \mathrm{~km} \cdot \mathrm{h}^{-1}$ ) (Krustrup and Bangsbo, 2001, Krustrup et al., 2009). HIR might also occur 60-100 times in a match (Krustrup and
Bangsbo, 2001, Krustrup et al., 2009). One study found that HIR in referees reduced towards the end of a match (Krustrup and Bangsbo, 2001), while another study found that HIR did not reduce (Krustrup et al., 2009). It is unclear whether referees in Japanese high-school (under-18; U-18) and university (under-22; U-22) level football matches show a decrease in HIR towards the end of a match. It would be valuable to obtain information on the temporal change in match performance of referees during youth top-level matches in order to improve the development of game planning and training programs. In most previous studies, match analysis demonstrated data into 15 -min periods. Thus, a more sensitive within-match analysis might improve our understanding of patterns of exercise intensity and the change in exercise intensities (Weston et al., 2011).

Previous studies reported that the physical de- 
mands (i.e., distance covered in selected activities, mean heart rate $[\mathrm{HR}]$, and rating of perceived exertion [RPE]) of referees were affected by the team standard and competitive level (Castagna et al., 2007, Mallo et al., 2009, Weston et al., 2006). In this regard, a previous study reported that the game style might affect the physical performance of football players during a match (Rienzi et al., 2000). Since the physical demands of referees during a match is associated with players' physical demands (Weston et al., 2007), referees might experience different demands according to the team style and match tempo. In fact, in youth football matches, the total distance covered (TD) of under-20 (U-20) players covered higher than that of under-17 (U-17) players, although the match duration was different (Pereira Da Silva et al., 2007). Therefore, it may be speculated that the physical demands of referees might be different between U-18 and U-22 league matches. To clarify this, it is important to determine the technical-tactical data of players in the same match.

No report in the relevant literature has described a study on referees in U-18 and U-22 football matches. Additionally, no studies are currently available on Japanese football referees. Information on referees could be of great importance for the development of specific training strategies in Japan. Thus, U-18 and U-22 football league matches represent a unique opportunity to assess the performance of Japanese referees and to confirm the physical demands of these referees and compare the physical demands and match performance with those of international top-level referees presented in previous studies (Castagna et al., 2007, Krustrup et al., 2009, Weston et al., 2012).

Therefore, this study aimed to examine the temporal change in the physical demands with respect to a referee's running distance and speed, and HR during Japanese U-18 and U-22 football matches, and to investigate the match technical-tactical data (number of passes, shots, fouls, offense-defense turnovers, and penetrations into the attacking zone). Additionally, we compared the physical demands and match performance of referees during U-18 and U-22 football league matches.

\section{Methods}

\subsection{Participants}

This study examined 20 male football referees holding a first-class $(n=7)$ or second-class $(n=13)$ license accredited by the Japan Football Association. The mean age, experience, height, weight, and body mass index (BMI) of the referees were $26.3 \pm$ 3.4 years, $7.6 \pm 2.6$ years, $1.75 \pm 0.05 \mathrm{~m}, 67.7 \pm 4.9$ $\mathrm{kg}$, and $22.1 \pm 1.3 \mathrm{~kg} \cdot \mathrm{m}^{-2}$, respectively. All participants were informed of the study methods, procedures, and risks, and all signed an informed consent document before participating in this study. This study was conducted according to the Declaration of Helsinki and was approved by the Ethics Committee for Human Experiments of Juntendo University.

\subsection{Experimental design}

Match data were collected from high-school (U-18) and university (U-22) top-level leagues in Japan (Kanto Prince League and the First Division of the Kanto University League) between September and November of 2011. The U-18 league was examined by 10 referees holding a second-class license, and the U-22 league was examined by 3 referees holding a second-class license and 7 holding a firstclass license. The match and half time durations were $90 \mathrm{~min}(45 \min \times 2)$ and $15 \mathrm{~min}$, respectively. The environmental conditions during the matches were as follows: mean ambient temperature, $28.2 \pm$ $5.2^{\circ} \mathrm{C}$; mean relative humidity, $58.7 \pm 19.2 \%$; and mean wet bulb globe temperature (WBGT), 25.4 \pm $4.4^{\circ} \mathrm{C}$, with no rainy day.

\subsection{Data collection and analysis}

\subsubsection{Physical performances}

Physical performances data were collected using a $15 \mathrm{~Hz}$ global positioning system (GPS) device (Sports performance indicator, SPI-Pro X2; GPSports, Australia) from 20 matches (one match dataset per referee). The GPS device was placed on the referee's upper back inside a pocket sewn into a specific undershirt. After the GPS device was placed at the last minute before warm-up, its operation was checked during warm-up. The validity and reliability of this system has been reported previously (Bar- 
bero-Alvarez et al., 2010). After the match, the recorded data were exported (Team AMS software; GPSports, Australia) for motion analysis. Based on a previous report (Ishihara et al., 2015), the movement speeds of the referees were classified into the following categories: (1) walking, $<6 \mathrm{~km} \cdot \mathrm{h}^{-1}$; (2) jogging, $6-8 \mathrm{~km} \cdot \mathrm{h}^{-1}$; (3) low-speed running (LSR), $8-12 \mathrm{~km} \cdot \mathrm{h}^{-1}$; (4) moderate-speed running (MSR), $12-15 \mathrm{~km} \cdot \mathrm{h}^{-1}$; (5) high-speed running (HSR), 15-18 $\mathrm{km} \cdot \mathrm{h}^{-1}$; and (6) sprinting, $\geq 18 \mathrm{~km} \cdot \mathrm{h}^{-1}$. HIR was defined as movement at a speed greater than $15 \mathrm{~km}$. $\mathrm{h}^{-1}$. The maximal speed during a match was selected from movements that lasted more than a second.

\subsubsection{HR and RPE}

HR was recorded using short-range radio telemetry (polar T34; Polar, Finland) and the GPS device. Each referee's individual maximum HR (HRmax) value was estimated using an age-predicted formula: 220-age. However, if a participant had a HR higher than the age-predicted value during the match, the peak value was adopted. In addition, the RPE was assessed using Borg's original scale (i.e., 6-20) (Borg, 1982) immediately after a match.

\subsubsection{Distance from a foul and players' technical and tactical data}

All matches were recorded using a broad video camera (HDR-CX560 V; Sony, Japan) to evaluate the referee's distance from a foul and the technical and tactical data of players or both teams during a match. The camera was positioned in the stands as an extension of the halfway line. The distance between the camera and the field was about $20-30 \mathrm{~m}$. The camera filmed the referee and players near the ball at a wide angle to evaluate the referee's distance from a foul and the tactical data of players or both teams. The distance from a foul was calculated based on a method used in a previous study (Aoba et al., 2011). In brief, the video was stopped temporarily each time a foul occurred. Then the spot where the referee signaled a foul and the spot at which a foul had occurred were transcribed to a paper of the football field on a scale of $1 / 400$. The distance between the spots was ascertained by drawing a straight line. To obtain the most accurate positions possible, we made marks representing the lines on the grass on the pitch, advertisements, and field lines. The same experienced observer analyzed all matches.
For the technical and tactical data of players or both teams during a match, the recordings were replayed and paused to isolate each aspect of the match, and measurements were obtained for the following items:

1. Passes: number of foot passes performed by a player

2. Shots: number of attempts to score

3. Fouls: number of fouls committed by a player during a match

4. Offense-defense turnovers: number of turnovers between the teams

5. Penetrations into the attacking zone: number of times that a team with the ball penetrated into the attacking zone (the area aside from $20 \mathrm{~m}$ on each side of the halfway line)

\subsection{Statistical analysis}

Data are presented as mean \pm SD. Differences between the first and second halves in the U-18 and U-22 matches were determined using the unpaired Student's $t$-test. Three-way mixed design ANOVAs (match-level $\times$ time $\times$ half) were used to compare the means of all physical performances and HR during a match. In addition, two-way mixed design ANOVAs (match-level $\times$ half) were used to compare the distance from a foul. For cases violating the assumption of sphericity, significance was adjusted using Greenhouse-Geisser adjustment. If significant effects were found, pairwise comparisons were performed using the Bonferroni method. Additionally, relations between the physical performances and distance from a foul were examined using Pearson's product moment correlation. All calculations were performed using SPSS software (ver. 17.0; SPSS Inc., USA). Statistical significance was set at $p<$ 0.05 .

\section{Results}

\subsection{Distance covered and movement speed}

The mean TD from the U-18 and U-22 matches were $11226 \pm 604 \mathrm{~m}$ and $11232 \pm 733 \mathrm{~m}$, respectively. Additionally, $17 \%$ of the distance $(1926 \pm 365 \mathrm{~m}$ and $1898 \pm 613 \mathrm{~m}$ ) was covered by HIR. For the mean running speed, the U-18 and U-22 matches were $7.13 \pm 0.40 \mathrm{~km} \cdot \mathrm{h}^{-1}$ and $7.09 \pm 0.44 \mathrm{~km} \cdot \mathrm{h}^{-1}$, respectively. The mean maximal speed during the 
$\mathrm{U}-18$ and $\mathrm{U}-22$ matches were $27.5 \pm 3.2 \mathrm{~km} \cdot \mathrm{h}^{-1}$ and $25.6 \pm 1.6 \mathrm{~km} \cdot \mathrm{h}^{-1}$, respectively. Figure 1 shows the distances covered by various movement categories during the U-18 and U-22 matches. These distance covered did not differ significantly between the U-18 and U-22 matches.

Figure 2 shows the TD and distance covered by HIR for referees during the U-18 and U-22 matches, recorded within each 5-min interval. Three-way mixed design ANOVAs (match-level $\times$ time $\times$ half) revealed that there was not significant main effect of match-level for the TD and distance covered by HIR. Moreover, a significant interaction was not found in match-level $\times$ time, match-level $\times$ half and match-level $\times$ time $\times$ half for these variables. No significant main effect and interaction were also found in match-level, match-level $\times$ time, match-level $\times$ half, and match-level $\times$ time $\times$ half for the distances covered by various movement categories and mean speed of referees (Table 1).

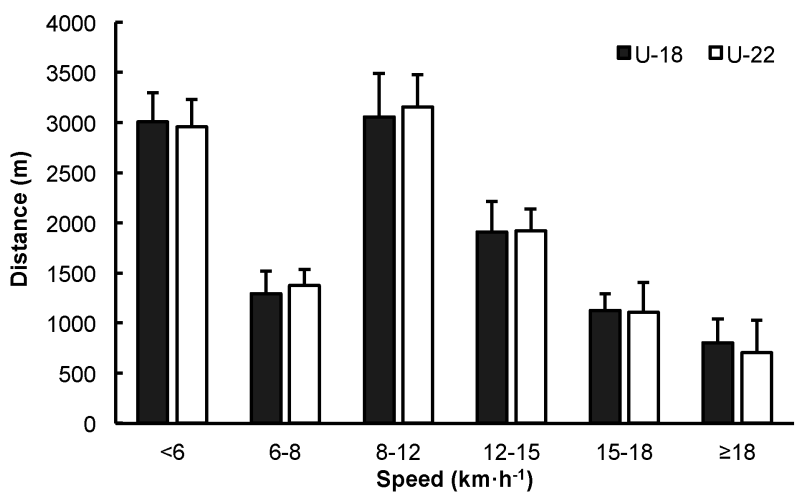

Figure 1 Distance covered by various movement categories during the U-18 (black bars) and U-22 (white bars) matches ( $n=10$ for each age category).

\subsection{HR and RPE}

The mean match HR from the U-18 and U-22 matches were $168 \pm 9$ beats $\cdot \min ^{-1}\left(86 \pm 5 \% \mathrm{HR}_{\max }\right)$ and $167 \pm 8$ beats $\cdot \mathrm{min}^{-1}\left(86 \pm 3 \% \mathrm{HR}_{\max }\right)$, respectively. The RPE values after the U-18 and U-22 matches were $15.1 \pm 1.6$ and $15.0 \pm 1.6$, respectively, and there was no significant difference. Figure 3
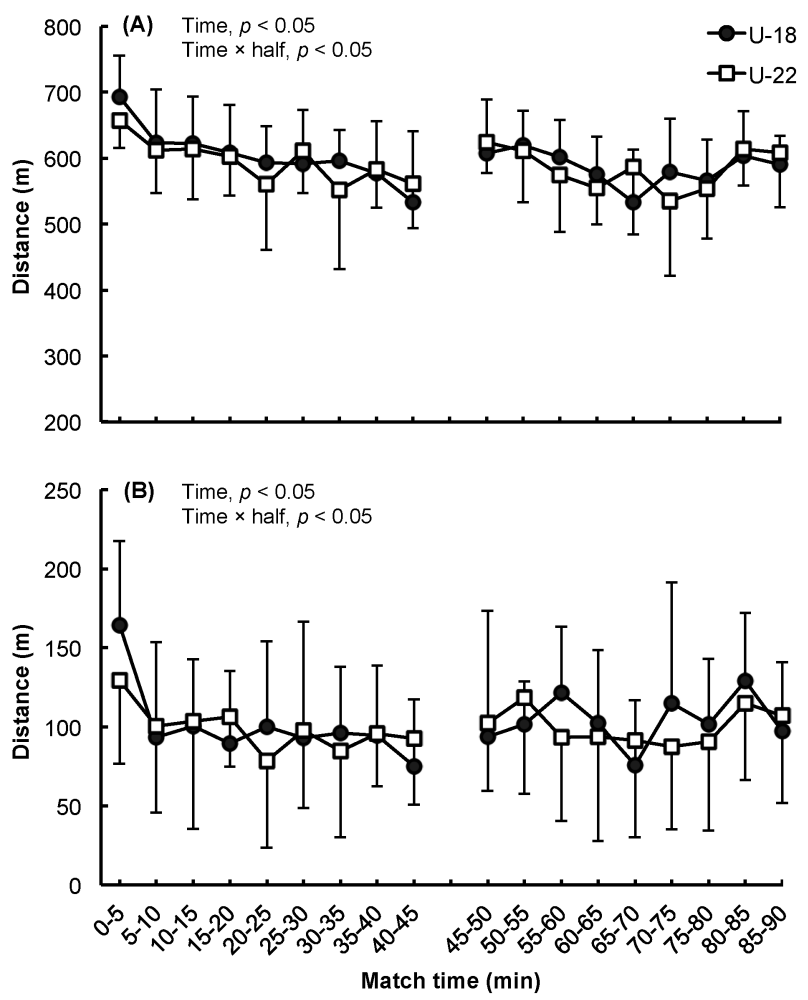

Figure 2 Total distance covered (A) and distance covered by HIR (B) for referees in the U-18 (black circles) and U-22 (white squares) matches, recorded within each 5 -min interval $(\mathrm{n}=10$ for each age category).

Table 1 The $p$ values for main effects of match-level, time and half and their interactions on match physical performance variables.

\begin{tabular}{|c|c|c|c|c|c|c|c|c|}
\hline \multirow{2}{*}{ Effect } & \multicolumn{7}{|c|}{ Distance } & \multirow{2}{*}{$\begin{array}{l}\text { Mean } \\
\text { speed }\end{array}$} \\
\hline & Total & Sprinting & HSR & MSR & LSR & Jogging & Walking & \\
\hline Match-level & 0.747 & 0.586 & 0.909 & 0.824 & 0.945 & 0.392 & 0.367 & 0.875 \\
\hline Time & $0.000^{*}$ & 0.087 & 0.067 & $0.000^{*}$ & $0.000^{*}$ & 0.676 & $0.000^{*}$ & $0.000 *$ \\
\hline Half & 0.111 & 0.693 & 0.761 & 0.751 & 0.067 & $0.007^{*}$ & 0.414 & 0.120 \\
\hline Match-level $\times$ time & 0.789 & 0.751 & 0.884 & 0.611 & 0.912 & 0.174 & 0.969 & 0.834 \\
\hline Match-level $\times$ half & 0.649 & 0.548 & 0.613 & 0.254 & 0.884 & 0.740 & 0.445 & 0.661 \\
\hline Time $\times$ half & $0.004^{*}$ & 0.692 & $0.004^{*}$ & $0.016^{*}$ & $0.026^{*}$ & 0.748 & $0.046^{*}$ & $0.005^{*}$ \\
\hline Match-level $\times$ half $\times$ time & 0.344 & 0.674 & 0.188 & 0.671 & 0.633 & 0.346 & 0.378 & 0.327 \\
\hline
\end{tabular}

\footnotetext{
* Significant main effect or interaction $(p<0.05)$.
}

Notes: High-speed running (HSR), $15-18 \mathrm{~km} \cdot \mathrm{h}^{-1}$; Moderate-speed running (MSR), $12-15 \mathrm{~km} \cdot \mathrm{h}^{-1}$; Low-speed running (LSR), 8-12 $\mathrm{km} \cdot \mathrm{h}^{-1}$. 


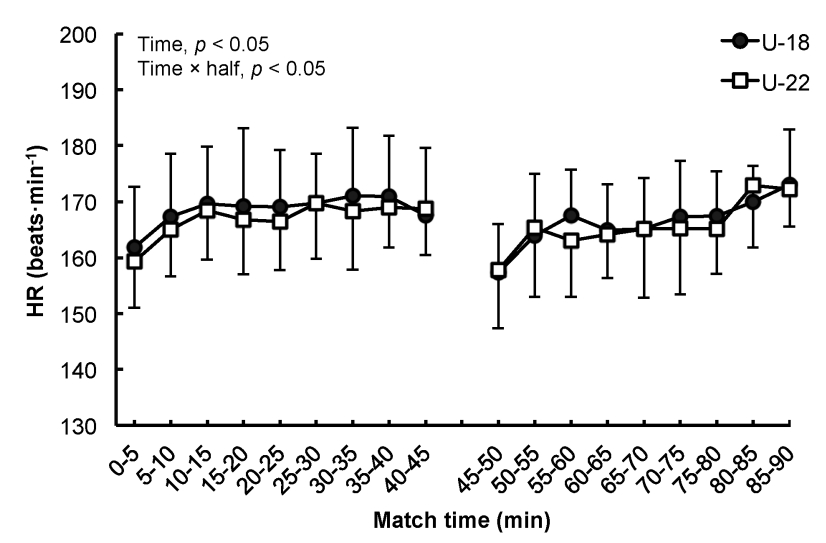

Figure 3 Mean match HR for referees in the U-18 (black circles) and U-22 (white squares) matches, recorded within each 5 -min interval $(n=10$ for each age category).

shows an overview of the mean match HR during the U-18 and U-22 matches. Three-way mixed design ANOVAs (match-level $\times$ time $\times$ half) revealed that there was not significant main effect of matchlevel for the mean match HR, whereas the main effect of time was significant. The interaction between time and half was significant. From Figure 2, it can be clarified that the significant interaction effect could be explained mainly by the tendency to increase the physical workload towards the end of the match. No significant interaction was found in match-level $\times$ time, match-level $\times$ half, or matchlevel $\times$ time $\times$ half for the mean match HR. In addition, the peak HRs during the U-18 and U-22 matches were $187 \pm 7$ beats $\cdot \mathrm{min}^{-1}$ and $192 \pm 9$ beats $\cdot \mathrm{min}^{-1}$, respectively $\left(176-200\right.$ beats $\cdot \mathrm{min}^{-1}$ for all referees), corresponding to $97 \%(91-100 \%)$ of the individual maximal HR.

\subsection{Distance from a foul}

The mean distances from a foul during the U-18 and U-22 matches were $14.8 \pm 1.3 \mathrm{~m}$ and $16.0 \pm 1.8$ $\mathrm{m}$, respectively, and there was no increase between the halves (first half: U-18 and U-22, $14.5 \pm 1.8 \mathrm{~m}$ and $16.2 \pm 1.6 \mathrm{~m}$; second half: U-18 and U-22, 15.0 $\pm 2.2 \mathrm{~m}$ and $15.5 \pm 3.0 \mathrm{~m}$, respectively). These measured variables did not differ significantly between the U-18 and U-22 matches. The mean distance from a foul was significantly correlated with the TD, HIR distance, and mean speed during matches (TD, $r=-0.70$; HIR, $r=-0.58$; mean speed, $r=-0.62, p<0.05)$.
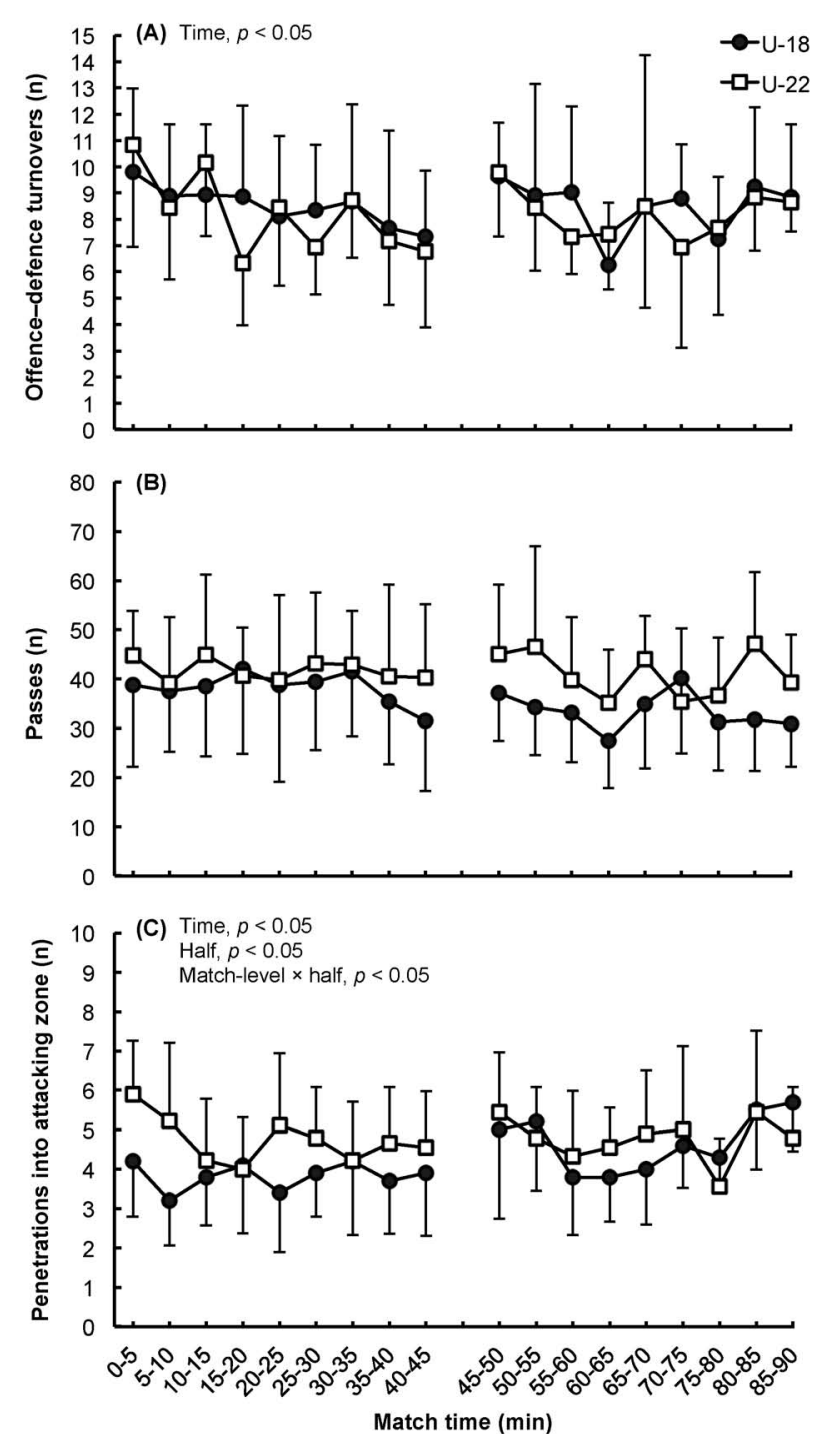

Figure 4 Numbers of offense-defense turnovers (A), passes (B) and penetrations into attacking zone $(C)$ in U-18 (black circles) and U-22 (white squares) matches, recorded within each 5 -min interval $(\mathrm{n}=10$ for $\mathrm{U}-18$, and $\mathrm{n}=9$ for $\mathrm{U}-22$ ).

\subsection{Technical and tactical data}

Figure 4 and 5 present overviews of the mean technical and tactical data during the U-18 and U-22 matches. The main effects of the match level were significant only for shots, which were higher for U-22 matches than for U-18 matches. Similarly, the interaction between match-level and half was significant. The main effects of time were significant for offense-defense turnovers and penetrations into the attacking zone. Moreover, the main effects of half were significant for fouls and penetrations into the attacking zone. The interaction between time and half was also significant for fouls. For passes, 

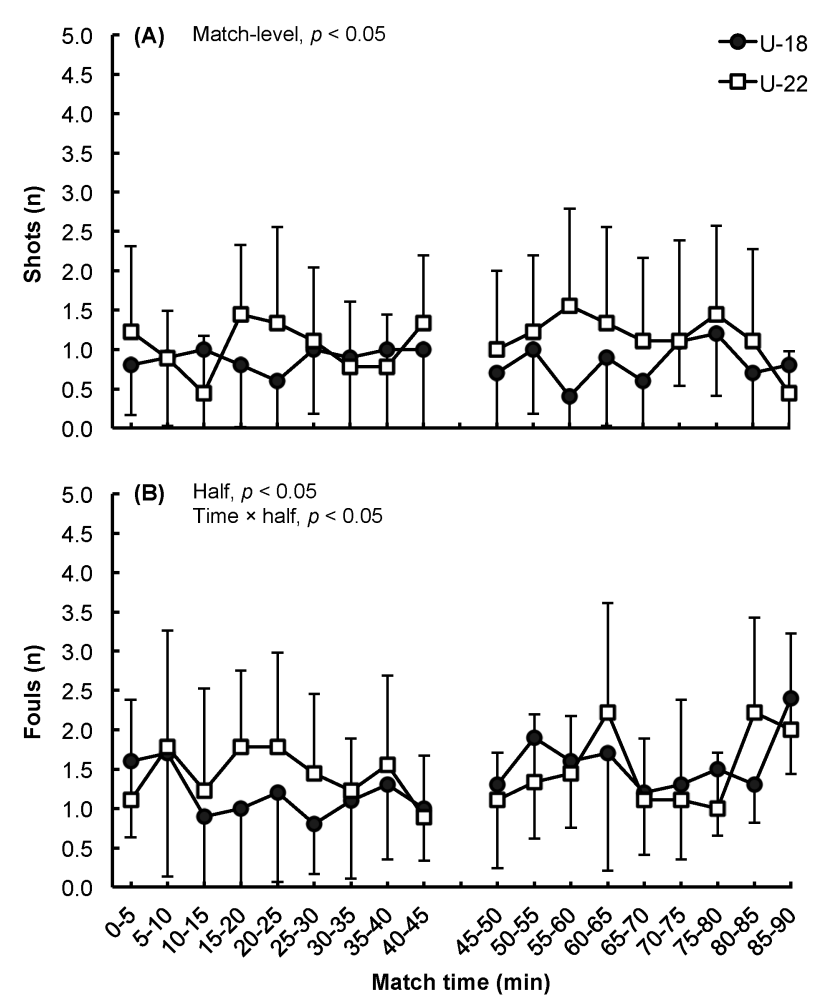

Figure 5 Numbers of shots (A) and fouls (B) in U-18 (black circles) and U-22 (white squares) matches, recorded within each 5 -min interval. Values are means \pm SD $(\mathrm{n}=10$ for $\mathrm{U}-18$, and $\mathrm{n}=9$ for U-22).

no significant main effect or interaction of the 3 factors was found.

\section{Discussion}

This study aimed to examine the temporal change in the physical demands with respect to a referee's running distance and speed, and HR during Japanese U-18 and U-22 football matches. Additionally, we compared the physical demands and match performance of referees during the U-18 and U-22 football league matches. As result, the total distance covered by referees between the U-18 and U-22 was $11226 \pm 604 \mathrm{~m}$ and $11232 \pm 733 \mathrm{~m}$, respectively, of which about $17 \%$ of the distance was covered by HIR $(1926 \pm 365 \mathrm{~m}$ and $1898 \pm 613 \mathrm{~m})$. The mean match $\mathrm{HR}$ was about $86 \%$ of $\mathrm{HR}_{\max }$, and the mean distance from a foul between the U-18 and U-22 was $14.8 \pm 1.3 \mathrm{~m}$ and $16.0 \pm 1.8 \mathrm{~m}$, respectively. Our results suggested that the physical demands and match performance of referees did not differ between the U-18 and U-22. These values were also similar to those of FIFA or domestic experienced referees assigned to top European leagues and international competition matches (Castagna et al., 2007, Krustrup and Bangsbo, 2001, Krustrup et al., 2009, Weston et al., 2011).

On investigating the technical-tactical data of field players during the same match, we found that the main effect of the match level and the interaction of the match level and half were significant only for shots (Figure 5). In short, irrespective of whether an attack could finish with a shot, it appears that attacks ended with a shot in the U-22 matches. For penetration into the attacking zone, the main effects of time and half were significant (Figure 4). This trend was stronger in the last stage of the match. Consequently, it is likely that the referee is required to move around each penalty area during such times. These findings, in addition to those expected from further research, might be beneficial for referee game planning in youth-level matches.

According to previously proposed analyses (Drust et al., 2007, Weston et al., 2011), we performed analyses at 5-min intervals. The TD and distance covered by HIR in the $0-5$ min after the kick-off were high demand during any other match period, and these variables tended to decrease toward the end of the first half. In the second half, these variables showed the same tendency as that in the first half until the middle of the half; however, the TD and distance covered by HIR tended to increase in the last $10 \mathrm{~min}$ of the match (Figure 2). A previous study found that HIR of referees reduced towards the end of a match (Krustrup and Bangsbo, 2001), while another study found that HIR did not reduce (Krustrup et al., 2009). Our findings are consistent with the findings of the latter study. A previous study on football players showed that substitutes who came on in the second half sprinted and ran at higher intensities (63\% and $25 \%$ more, respectively) during the final $15 \mathrm{~min}$ of a match compared to the intensities of players who had played the entire match (Mallo et al.. 2009). Other studies reported that more goals were scored toward the end of a match than at any other time (Ekblom, 1994) and that injuries occurred at a high rate during the final 15 min of each half (Hawkins and Fuller, 1999). In addition, considering tactical adjustments, such as shifts to long-pass strategies, and our findings of the technical-tactical data, HIR of referees might increase in the last stages of a match. We found that the TD and HR increased during the last $10 \mathrm{~min}$ of 
a match. Thus, it was considered that referees in youth-level matches have reserve capacity to carry out high-intensity activities even in the late stages of a match.

In the 5-min interval analysis conducted in the present study, similar low values of the mean HR were found in the first $5 \mathrm{~min}$ of both halves. The HR tended to be constant until the end of the first half, but it tended to increase to $15 \mathrm{~min}$ immediately after kick-off. In the second half, although the same phenomenon of the first half continued, the HR tended to increase more in the last $10 \mathrm{~min}$ of the match. Our results are similar to those of previous studies (Helsen and Bultynck, 2004, Weston et al., 2006). Football referees supervise an intermittent sport in which the aerobic energy system is highly taxed with respective average and peak values of $80-90 \%$ and $95-100 \%$ (Krustrup and Bangsbo, 2001, Reilly and Gregson, 2006), and the referee changes the activity mode approximately every 4-6 s from low-intensity activities, such as jogging and walking, to medium-intensity activities and HIR (Krustrup and Bangsbo, 2001). Considering such an intermittent activity mode, an increase in the HR occurs toward sustained activity because of cardiovascular drift (Catterall et al., 1993). Cardiovascular drift is exacerbated by numerous factors, such as dehydration and heat stress (Achten and Jeukendrup, 2003). Therefore, the increased mean match HR at the end of the match might be due to dehydration, elevated body temperature, and increased high-intensity activities with as a result of tactical change.

In the previous study, the match intensity, as inferred from HR data and RPE, was higher in the English Premier League than in other English Football League matches, suggesting that physical and emotional stresses among referees were correlated with the match competition level (Weston et al., 2006). However, the mean HR and RPE after the match were not significantly different between the U-18 and U-22 matches, suggesting that the physiological strain and subjective fatigue of referees are similar between U-18 and U-22 matches.

To assess physical performance aside from the match variables described above, previous studies examined the distance from a foul (Krustrup and Bangsbo, 2001, Krustrup et al., 2009, Weston et al., 2010), which is a good indicator of the referee's ability to keep up with play. In the present study, the mean distances from a foul during the U-18 and U-22 matches were $14.8 \pm 1.3 \mathrm{~m}$ and $16.0 \pm 1.8 \mathrm{~m}$, respectively, and there was no increase between the halves. These values, about $15 \mathrm{~m}$ on average, were similar to those reported in previous studies (Krustrup et al., 2009, Weston et al., 2010). The lowest error rate was achieved when distances were 11-15 $\mathrm{m}$ (Mallo et al., 2012). In short, the referees in this study moved while maintaining the distance from a foul at about $15 \mathrm{~m}$, indicating that these referees were able to keep up with play as good as a top-class referee. A previous study showed that the mean distance from a foul was negatively correlated with the HIR distance (Krustrup et al., 2009). In this study, similar observations were confirmed. In addition, the TD and mean speed showed similar correlations. Both HIR and the distance from a foul during play were controlled sufficiently by referees. They could run at low and moderate intensity, and cover the game action based on their level of fitness. More experienced referees might better predict future events and use clever positioning (Weston et al., 2010), minimizing unnecessary movements in order to make judgments. Thus, the TD was strongly correlated with the distance from a foul than HIR in this study. Based on our results and the findings of previous studies, we suggest that referees should possess an optimal physical capacity to be able to follow play until the latter stages of a match. In addition, the distance from a foul is useful as an indicator to assess the match performance of referees at all competitive levels.

Our results were limited to a small number of football matches that were played during the U-18 and U-22 top-level. Although our results warrant further confirmation through additional studies with greater sample sizes, it is important to consider that the Japanese youth top-level leagues provided a unique opportunity for studying the Japanese football referees. The referees in this study differed between the U-18 and U-22 matches. Further studies are needed to analyze the time-motion data in which a referee judged both the U-18 and U-22 matches, and to investigate the physical demands and match performance of referee in the other senior categories (Japan football league and/or Japan Professional Football League) and the matches with female players. 


\section{Conclusion}

Our findings showed that the physical demands temporarily increased in the last stage of a match. We also found that the number of penetrations into the attacking zone and fouls increased at the same stage, suggesting that the referees of U-18 and U-22 matches are required to extensively move around each penalty area and keep up with play during this period. Additionally, it is suggested that the physical demands and match performances of referees are not different between the U-18 and U-22 matches. These findings might be beneficial for game planning of football referees and might be beneficial for their instructors and other professionals involved in the development of training programs that effectively enhance sport-specific fitness and involved in coaching of young football referees.

\section{Acknowledgements}

This study was supported by the Institute of Health and Sports Science \& Medicine, Juntendo University. We would like to thank all participants for their participation and effort. We also thank the Refereeing Department of the Kanto Region Football Association for their assistance in data collection.

\section{References}

Achten, J. and Jeukendrup, A. E. (2003). Heart rate monitoring: applications and limitations. Sports Med., 33: 517-538.

Aoba, Y., Yoshimura, M., Miyamori, T., and Suzuki, S. (2011). Assessment of soccer referee performance during games. Football Science, 8: 8-15.

Barbero-Alvarez, J. C., Coutts, A., Granda, J., BarberoAlvarez, V., and Castagna, C. (2010). The validity and reliability of a global positioning satellite system device to assess speed and repeated sprint ability (RSA) in athletes. J Sci. Med. Sport., 13: 232-235.

Borg, G. A. (1982). Psychophysical bases of perceived exertion. Med. Sci. Sports Exerc., 14: 377-381.

Castagna, C., Abt, G., and D'Ottavio, S. (2007). Physiological aspects of soccer refereeing performance and training. Sports Med., 37: 625-646.

Catterall, C., Reilly, T., Atkinson, G., and Coldwells, A. (1993). Analysis of the work rates and heart rates of association football referees. Br. J. Sports Med., 27: 193-196.

Drust, B., Atkinson, G., and Reilly, T. (2007). Future Perspectives in the Evaluation of the Physiological Demands of Soccer. Sports Med., 37: 783-805.

Ekblom, B. (1994). Football (Soccer). Oxford: Blackwell Scientific Publications.

Hawkins, R. D. and Fuller, C. W. (1999). A prospective epidemiological study of injuries in four English professional football clubs. Br. J. Sports Med., 33: 196-203.

Helsen, W. and Bultynck, J. B. (2004). Physical and perceptual-cognitive demands of top-class refereeing in association football. J. Sports Sci., 22: 179-189.

Ishihara, Y., Naito, H., Ozaki, H., and Yoshimura, M. (2015). Aerobic Fitness Relation to Match Performance of Japanese Soccer Referees. Football Science, 12: 91-97.

Krustrup, P. and Bangsbo, J. (2001). Physiological demands of top-class soccer refereeing in relation to physical capacity effect of intense intermittent exercise training. J. Sports Sci., 19: 881-891.

Krustrup, P., Helsen, W., Randers, M. B., Christensen, J. F., MacDonald, C., Rebelo, A. N., and Bangsbo, J. (2009). Activity profile and physical demands of football referees and assistant referees in international games. J. Sports Sci., 27: 1167-1176.

Mallo, J., Frutos, P. G., Juarez, D., and Navarro, E. (2012). Effect of positioning on the accuracy of decision making of association football top-class referees and assistant referees during competitive matches. J. Sports Sci., 30: 1437-1445.

Mallo, J., Navarro, E., Aranda, J. M., and Helsen, W. F. (2009). Activity profile of top-class association football referees in relation to fitness-test performance and match standard. J. Sports Sci., 27: 9-17.

Pereira Da Silva, N., Kirkendall, D.T., and Leite De Barros Neto, T. (2007). Movement patterns in elite Brazilian youth soccer. J. Sports Med. Phys. Fitness, 47: 270-275.

Reilly, T. and Gregson, W. (2006). Special populations: the referee and assistant referee. J. Sports Sci., 24: 795-801.

Rienzi, E., Drust, B., Reilly, T., Carter, J. E. L., and Martin, A. (2000). Investigation of anthropometric and work-rate profiles of elite South American international soccer players. J. Sports Med. Phys. Fitness, 40: 162-169.

Weston, M., Bird, S., Helsen, W., Nevill, A., and Castagna, C. (2006). The effect of match standard and referee experience on the objective and subjective match workload of English Premier League referees. J. Sci. Med Sport, 9: 256-262.

Weston, M., Castagna, C., Impellizzeri, F., Bizzini, M., Williams, A. M., and Gregson, W. (2012). Science and Medicine Applied to Soccer Refereeing An Update. Sports Med., 42: 615-631.

Weston, M., Castagna, C., Impellizzeri, F., Rampinini, E., and Abt, G. (2007). Analysis of physical match performance in English Premier League soccer referees with particular reference to first half and player work rates. J. Sci. Med Sport, 10: 390-397.

Weston, M., Castagna, C., Impellizzeri, F., Rampinini, E., and Breivik, S. (2010). Ageing and physical match performance in English Premier League soccer referees. J. Sci. Med. Sport, 13: 96-100.

Weston, M., Drust, B., and Gregson, W. (2011). Intensities of exercise during match-play in FA Premier League referees and players. J. Sports Sci., 29: 527-532. 


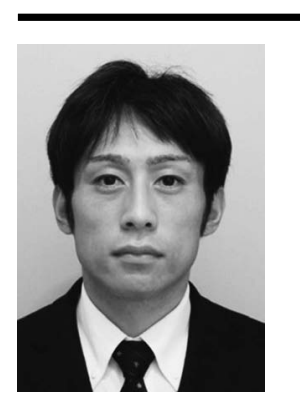

Name:

Yoshihiko Ishihara

Affiliation:

Institute of Health and Sports Science \& Medicine, Juntendo University

Address:

1-1 Hirakagakuendai, Inzai, Chiba 270-1695, Japan

Brief Biographical History:

2015- present, Postdoctoral Fellow, Institute of Health and Sports Science \& Medicine, Juntendo University.

2012-2015, Ph.D., Graduate School of Health and Sports Science, Juntendo University.

2010-2012, M.S., Graduate School of Health and Sports Science, Juntendo University.

Main Works:

-Ishihara, Y., Ozaki, H., Nakagata, T., Ishibashi, M., Machida, S., and Naito, H. (2016) Locomotive syndrome relation to daily physical activity, physical function, and body composition in elderly people: a pilot study. Juntendo Medical Journal. Vol. 62, Suupl 1: 225-230.

-Ishihara, Y., Naito, H., Ozaki, H., and Yoshimura, M. (2015) Aerobic fitness relation to match performance of Japanese soccer referees. Football Science Vol.12, 91-97.

Membership in Learned Societies:

- Japan Society of Physical Education, Health and Sports Sciences

- Japan Society of Human Growth and Development

- Japanese Society of Physical Fitness and Sports Medicine

- Japanese Society of Science and Football

- Japanese Society of Health, Fitness and Nutrition 